\title{
Corrigendum: Melatonin: Current Status and Future Perspectives in Plant Science
}

\author{
Muhammad A. Nawaz ${ }^{1,2 \dagger}$, Yuan Huang ${ }^{1 \dagger}$, Zhilong Bie ${ }^{1 *}$, Waqar Ahmed ${ }^{3}$, Russel J. Reiter ${ }^{4}$, \\ Mengliang Niu ${ }^{1}$ and Saba Hameed ${ }^{1}$ \\ ${ }^{1}$ Key Laboratory of Horticultural Plant Biology, College of Horticulture and Forestry Sciences, Huazhong Agricultural \\ University, Ministry of Education, Wuhan, China, ${ }^{2}$ Department of Horticulture, University College of Agriculture, University of \\ Sargodha, Sargodha, Pakistan, ${ }^{3}$ Sector Advisor-Horticulture, USAID-CNFA, Lahore, Pakistan, ${ }^{4}$ Department of Cellular and \\ Structural Biology, University of Texas Health Science Center at San Antonio, San Antonio, TX, USA
}

Keywords: melatonin, biosynthesis, physiological functions, antioxidants, root growth, stress tolerance

\section{A corrigendum on}

Melatonin: Current Status and Future Perspectives in Plant Science by Nawaz, M. A., Huang, Y., Bie, Z., Ahmed, W., Reiter, R. J., Niu, M., et al. (2016). Front. Plant Sci. 6:1230. doi: 10.3389/fpls.2015.01230

\section{OPEN ACCESS}

Edited and reviewed by:

Haitao Shi,

Hainan University, China

*Correspondence: Zhilong Bie

biezhilong@hotmail.com

${ }^{\dagger}$ These authors have contributed equally to this work

Specialty section: This article was submitted to Plant Metabolism and Chemodiversity, a section of the journal Frontiers in Plant Science

Received: 22 April 2016 Accepted: 09 May 2016

Published: 24 May 2016

Citation:

Nawaz MA, Huang Y, Bie Z, Ahmed W, Reiter RJ, Niu M and Hameed S (2016) Corrigendum: Melatonin: Current Status and Future Perspectives in Plant Science.

Front. Plant Sci. 7:714 doi: 10.3389/fp/s.2016.00714

\section{BIOSYNTHESIS}

The readers are informed that the text given in the biosynthesis section of originally published article (doi: 10.3389/fpls.2015.01230) at line number 20-30 of page number two is not definitive and has very limited scientific evidence, so it should not be considered.

Some steps illustrated in originally published Figure 1, like the conversion of tryptamine to Indo3 -acetaldehyde and indole acetic acid (IAA), and direct conversion of serotonin to melatonin by SNAT are not definitive, as they have very limited scientific evidence. So these steps should not be considered the part of originally published Figure 1.

\section{AUTHOR CONTRIBUTIONS}

All authors listed, have made substantial, direct, and intellectual contribution to the work, and approved it for publication.

\section{REFERENCES}

Arnao, M. B., and Hernandez-Ruiz, J. (2014). Melatonin: plant growth regulator and/or biostimulator during stress? Trends Plant Sci. 19, 789-797. doi: 10.1016/j.tplants.2014.07.006

Conflict of Interest Statement: The authors declare that the research was conducted in the absence of any commercial or financial relationships that could be construed as a potential conflict of interest.

Copyright (c) 2016 Nawaz, Huang, Bie, Ahmed, Reiter, Niu and Hameed. This is an open-access article distributed under the terms of the Creative Commons Attribution License (CC BY). The use, distribution or reproduction in other forums is permitted, provided the original author(s) or licensor are credited and that the original publication in this journal is cited, in accordance with accepted academic practice. No use, distribution or reproduction is permitted which does not comply with these terms. 


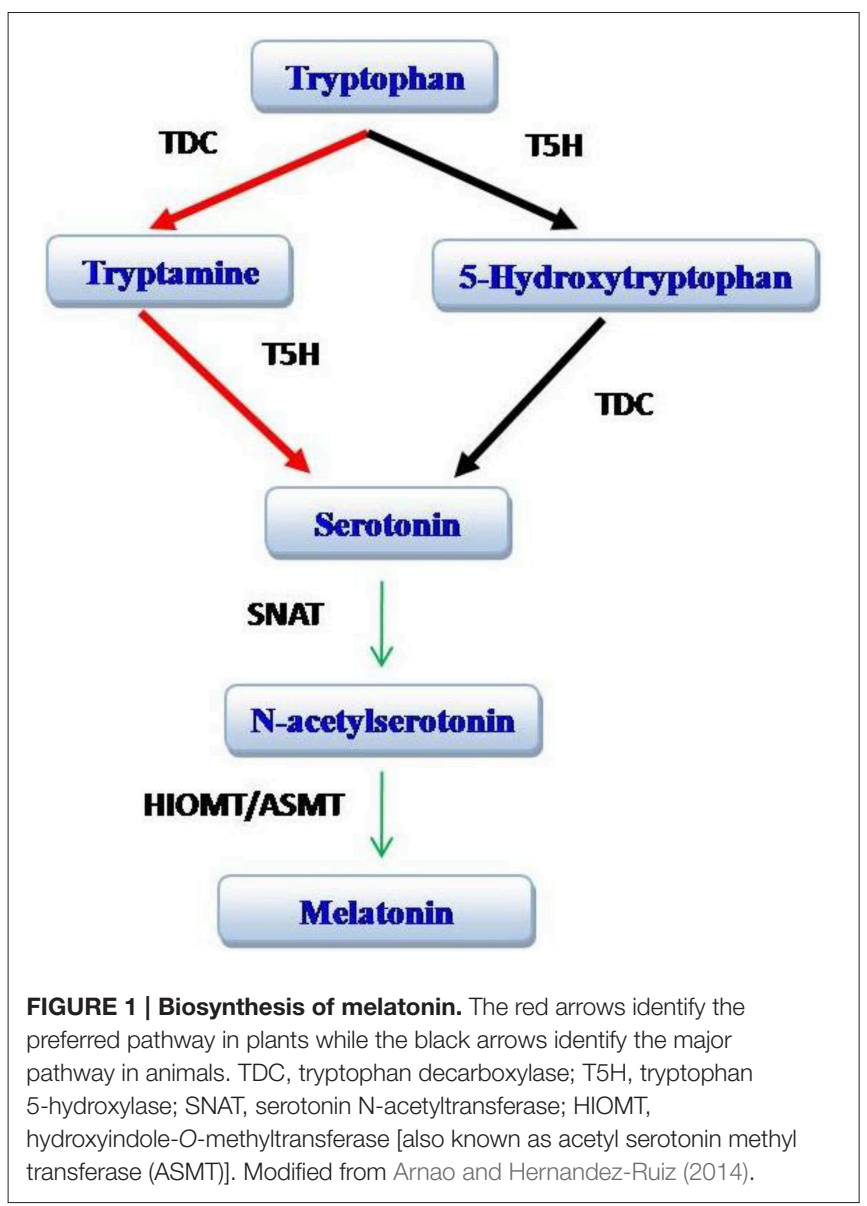

